\title{
Burden of Oral Symptoms and Its Associations With Nutrition, Well-Being, and Survival Among Nursing Home Residents.
}

\section{Lindroos, Eeva K.}

2019-05

Lindroos , E K, Saarela , R K, Suominen, M H , Muurinen , S , Soini , H , Kautiainen , H \& Pitkälä , K H 2019 , ' Burden of Oral Symptoms and Its Associations With Nutrition, Well-Being, and Survival Among Nursing Home Residents. ' , Journal of the American Medical Directors Association , vol. 20 , no. 5 , pp. 537-543 . https://doi.org/10.1016/j.jamda.2018.10.025

http://hdl.handle.net/10138/307974

https://doi.org/10.1016/j.jamda.2018.10.025

acceptedVersion

Downloaded from Helda, University of Helsinki institutional repository.

This is an electronic reprint of the original article.

This reprint may differ from the original in pagination and typographic detail.

Please cite the original version. 


\section{Burden of oral symptoms and its associations with nutrition, well-being, and survival among nursing home residents}

Eeva K Lindroos MSc ${ }^{\text {a }}$, Riitta K Saarela PhD ${ }^{\mathrm{b}}$, Merja H Suominen $\mathrm{PhD}^{\mathrm{a}}$, Seija Muurinen $\mathrm{PhD}^{\mathrm{a}}$, Helena Soini $\mathrm{PhD}^{\mathrm{c}}$ Hannu Kautiainen PhD ${ }^{\mathrm{d}}$, Kaisu H Pitkala MD,PhD ${ }^{\mathrm{f}}$

${ }^{\text {a }}$ University of Helsinki, Department of General Practice, Helsinki, Finland

${ }^{\mathrm{b}}$ City of Helsinki, Social Services and Health Care Sector, Oral Health Care, Helsinki, Finland

${ }^{c}$ City of Helsinki, Department of Social Services and Health Care, Developmental and Operational Support, Helsinki, Finland

${ }^{\mathrm{d}}$ Helsinki University Central Hospital - Unit of Primary Health Care, University of Helsinki, Helsinki, Finland

${ }^{\mathrm{f}}$ University of Helsinki, Department of General Practice and Helsinki University Central Hospital, Unit of Primary Health Care

Correspondence to:

Kaisu Pitkälä

Professor

University of Helsinki, Department of General Practice and Primary Health Care

PO Box 20

00014 University of Helsinki, Finland

email: kaisu.pitkala@helsinki.fi

tel. $+358-50-3385546$

The word count: 2940 


\section{Abstract}

2

3 Objectives: To explore how oral problems: chewing problems, dry mouth, and swallowing

4 difficulties cluster and whether their burden is associated with nutritional status, eating habits,

5 gastrointestinal symptoms, psychological well-being, and mortality among institutionalized

6 residents.

7 Design: Cross-sectional study with 1-year mortality.

8 Setting and participants: 3123 residents living in assisted facilities and nursing homes in 9 Helsinki, Finland.

Measures: Trained nurses assessed residents in all nursing homes and assisted living facilities in Helsinki in 2011. A personal interview, the Mini Nutritional Assessment (MNA), oral symptoms, questions about eating habits, and psychological well-being were used to assess each resident. We divided the subjects first according to the number of oral symptoms into four groups: No oral symptoms (G0), one oral symptom (G1), two oral symptoms $(\mathrm{G} 2)$, and all three symptoms (G3) and second according to the symptoms: dry mouth, chewing problems and swallowing difficulties. The diagnoses and medications were retrieved from medical records and mortality data were obtained from central registers.

Results: In all, $26 \%$ of the subjects had one oral problem (G1), $11 \%$ had two oral problems (G2), and 4\% had all three oral problems (G3), whereas $60 \%(n=1870)$ had no oral symptoms. Thus, the oral symptoms moderately overlapped. The burden of oral symptoms was linearly associated with malnutrition, higher numbers of comorbidities, dependency in physical functioning, gastrointestinal symptoms, eating less and more often alone. The higher the burden of oral symptoms, the lower the self- 
24 rated health and psychological well-being. Mortality increased along with the higher oral symptoms burden. Of residents, having one or more symptoms $26 \%$ had chewing problems, $18 \%$ swallowing difficulties and $15 \%$ dry mouth.

27 Conclusions/Implications: The burden of oral health problems was associated in a stepwise fashion with poor health and psychological well-being, malnutrition, and mortality. Clinicians should routinely assess older institutionalized residents' oral health status to improve residents' well-being.

31 Keywords: Dry mouth, chewing problems, swallowing difficulty, psychological wellbeing, mortality, oral health 


\section{Introduction}

Oral symptoms such as dry mouth, ${ }^{1-3}$ chewing problems, ${ }^{3-5}$ and swallowing difficulties ${ }^{6-8}$ are common among vulnerable older people. Individual symptoms are associated with malnutrition, disabilities, and comorbidities, especially among institutionalized older people. ${ }^{1-5,7,9,10}$

Dry mouth is defined as a subjective sensation of dryness in the mouth that is often referred to as xerostomia. ${ }^{2}$ The prevalence of xerostomia in community-dwelling older people has ranged from $17 \%$ to $62 \% .{ }^{1,11}$ In the institutionalized elderly, the prevalence has ranged from $20 \%$ to $78 \% .^{1}$ The prevalence was more than $55 \%^{1}$ particularly among older people living with systemic diseases, such as diabetes, Parkinson disease, and cancer. Medications may work synergistically impairing function of salivary glands, decreasing discharge of saliva. ${ }^{1}$ Dry mouth may have negative impacts on oral health, such as caries and fungal infection. ${ }^{1}$ Decreased saliva secretion alters food taste and may negatively impact the enjoyment of eating. $^{12}$

The number and distribution of teeth influence eating abilities. ${ }^{13}$ The proportion of edentulous subjects varies between $23 \%$ and $74 \%$ in institutional settings. ${ }^{14}$ The processing of food for digestion starts in the mouth and is dependent on the ability to chew and masticatory functions that are influenced by tooth loss, various diseases, muscle strength, disabilities, and medications. ${ }^{15}$ Moreover, saliva secretion is needed to form comminuted food into a lubricated concise bolus that is easier to swallow. ${ }^{1,2,15}$ Previous studies have shown that chewing problems are associated with older age, malnutrition, poor eating, and disabilities, and may predict mortality. 9,13

The prevalence of swallowing difficulties in long-term care establishments has varied between $12 \%$ and $60 \%$, depending on the setting and assessment method. ${ }^{7,10,16}$ Swallowing 
problems are associated with malnutrition, disabilities, and comorbidities and may also predict mortality. ${ }^{7,8,16}$

Although individual oral problems have been increasingly studied among vulnerable older people, including residents in long-term care establishments, few studies have explored how oral health problems overlap and how their burden ${ }^{3}$ is associated with nutritional factors, well-being, symptoms and diseases. The aim of this study is to assess how oral health problems (dry mouth, chewing problems and swallowing difficulties) cluster with each other and how the burden of as well as various oral symptoms separately are associated with nutritional status, eating habits, health factors, gastrointestinal (GI) symptoms, psychological well-being, and mortality among residents living in institutional care establishments in Helsinki, Finland.

\section{Methods}

The study population comprised all residents dwelling in assisted living facilities and nursing homes in Helsinki in 2011. The original study was designed to assess residents' nutritional status and nutritional care in these settings. In Finland assisted-living facilities are very similar to traditional nursing homes with respect to resident characteristics and in having 24hour nursing assistance, ${ }^{17}$ but they are more homelike. They also include group homes for people with dementia. The response rate of the study was $72 \%(\mathrm{~N}=3188)$. Those not responding either refused or suffered from moderate to severe dementia and did not have a proxy to give an informed consent $(n=1261)$. In addition, we excluded those residents not having the data concerning oral symptoms $(n=65)$. This study includes all residents having information on three oral symptoms (dry mouth, chewing problems, swallowing difficulties) and mortality $(\mathrm{N}=3123)$. The data of this cross-sectional study were collected in 2011 by registered nurses who were close caregivers to the residents. They were trained in a one full 
day hands-on training to complete questionnaires by assessing each resident. All items in the questionnaire were discussed in this training sessions. Nurses were also guided to inquire residents about several items such as psychological well-being. The structured questionnaire was used in two previous nutrition studies in nursing homes and assisted living facilities in Finland. ${ }^{18,19}$

The questionnaire included socio-demographic variables (age, sex, education) and medical records, used to retrieve current medical diagnoses and use of medications. Comorbidity was calculated for each participant, using Charlson's comorbidity index. ${ }^{20}$ One-year mortality was retrieved from central registers. Anticholinergic drugs were defined according to the Anticholinergic Risk Scale. ${ }^{21}$

Chewing and swallowing problems, and oral symptoms concerning dry mouth were referred to by the yes/no questions: "Does the resident suffer from chewing problems?", "Does the resident have a dry mouth?", and "Does the resident suffer from swallowing difficulties?" The nurses' evaluations were based on bedside assessment, and observation of the residents while eating and swallowing. The nurses were trained to assess each resident's mouth problems (dental status, dryness of mouth). They were also trained to recognize swallowing disorder. Specific tests were not used for swallowing or secretion of saliva. The dentition status of residents was categorized, according to the type of dentition, in five groups: 1) edentulous without dentures, 2) edentulous with complete dentures in the upper and lower jaws, 3) edentulous, upper or lower complete denture, 4) natural teeth with one or more dentures (mixed dentition) or 5) natural teeth only.

The resident's nutritional status was assessed with the Mini Nutritional Assessment (MNA). ${ }^{22}$ Each subject was categorised as having good nutrition (24-30 points), being at risk of malnutrition $(17-23.5)$ or being malnourished $(<17) .{ }^{22}$ Feeding was assessed in three 
categories: eats independently, eats with some assistance and unable to eat without assistance. GI symptoms ( constipation, diarrhoea, and vomiting) were charted with yes/no options.

The consistency of the food offered was divided into two groups: normal or soft and pureed, or liquid food. The average proportion of food consumed by residents was assessed with the question: How much on average does the resident eat of the main meal? The nurses were instructed to compare this proportion with model portions, for which images were available. The average amount of a meal consumed was dichotomized as eating adequately (eats very much, quite much, and normally) and eating little (quite little or little). The use of protein- or energy-rich meals, and oral protein-energy supplements was inquired with yes/no questions.

The subjects' cognitive and physical functioning were assessed with well-validated questions retrieved from the Clinical Dementia Rating (CDR) scale. ${ }^{23}$ The subject's stage of cognition was evaluated according to the stage 'at least moderate cognitive decline': CDR 'memory' item $\geq 2$. The subject's physical functioning was considered dependent if the CDR 'personal care' item was $\geq 2$.

The psychological well-being was assessed, using six questions about (1) life satisfaction (yes/no), (2) feeling needed (yes/no), (3) having plans for the future (yes/no), (4) having zest for life (yes/no), (5) feeling depressed (seldom or never/sometimes/often or always), (6) suffering for loneliness (seldom or never/ sometimes/often or always). The psychological well-being score ${ }^{24}$ was created from questions in which each question represented 0 points (no in questions $1-4$, often or always' in questions 5 or 6 ), 0.5 points (sometimes in questions 5 or 6 ), or 1 point (yes in questions $1-4$, seldom or never in questions 5 or 6 ). The total amount of points was then divided by the number of questions the residents were able to answer. Thus, a score of 1 represented the best well-being and 0 the poorest. These questions have been used in a number of studies, ${ }^{24-26}$ and the validity ${ }^{25}$ and reliability ${ }^{26}$ of the scale 
have been evaluated. Residents' self-rated health was inquired by a question 'How do you rate your current health status?' $(1=$ healthy, $2=$ quite healthy, $3=$ unhealthy and $4=$ very unhealthy). Those answering healthy and quite healthy were considered as having good selfrated health. Those residents unable to answer, due to severe dementia, were not included in the psychological well-being and self-rated health items.

The residents were grouped (G0, G1, G2, G3) as having no, one, two, or three oral symptoms (symptoms in chewing, swallowing, dry mouth). A Venn diagram was created to illustrate the clustering and burden of oral symptoms. In addition, residents were grouped according to their symptoms: dry mouth, chewing problems and swallowing difficulties. The categorical variables were described as percentages $(\%)$, the continuous variables as means and standard deviations (SDs). The demographic and clinical characteristics of the participants in the groups were compared. Statistical significance for the hypotheses of linearity was evaluated, using analysis of variance (ANOVA), the Cochran-Armitage test, or logistic models. In the case of violation of the assumptions (e.g. non-normality), a bootstrap-type test was used. Difference between oral symptoms groups were evaluated using generalized estimating equations (GEE) with appropriate distribution and link function. To determine characteristics associated with burden of oral symptoms, multivariate forward stepwise ordered logistic regression analysis were applied. Mortality analyses were performed with the Log-rank test and Cox regression models. The normality of the variables was tested, using the ShapiroWilk W-test. All analyses were performed using STATA software version 14.0 (StataCorp LP, College Station, TX, USA).

All the study procedures have been performed according to Helsinki Declaration. The Ethics Committee of Helsinki Central Hospital and City of Helsinki (Ethical committee of medicine) approved this study. The participation in this study was voluntary. Each participant or his/her closest proxy gave written consent to participate before the commenced the study procedure. 


\section{Results}

Of all participants, $40 \%(n=1253)$ had at least one oral symptoms, $15 \%(n=462)$ with dry mouth, $26 \%(\mathrm{n}=817)$ with problems in chewing, or $18 \%(\mathrm{n}=548)$ with difficulties in swallowing. The oral symptoms moderately overlapped. Of these subjects, $26 \%$ had one oral problem (G1), 11\% had two oral problems (G2), and 4\% had all three oral problems (G3), whereas $60 \%(n=1870)$ had no oral symptoms (Figure 1). Of all participants $15 \%$ had dry mouth, $26 \%$ had chewing problems and $18 \%$ swallowing difficulties.

Table 1 presents the demographic and health characteristics of the study population, divided into groups according to the burden of oral symptoms and the table 2 in groups divided according to oral symptoms. The mean age of the study participants was 84 years, $77 \%$ being females. The burden of oral symptoms was associated with more advanced age, higher numbers of comorbidities, and poorer self-rated health. Nursing home residents had higher burden of oral symptoms than those living in assisted living facilities. There was also a linear relationship between the higher number of oral symptoms and stroke and Parkinson disease. In addition, a linear relationship was not observed between the higher number of medications, use of anticholinergic drugs, and lower number of oral symptoms. The more the participants had oral symptoms, the more often they were dependent on their physical functioning and unable to walk independently inside. In addition, there was a linear relationship between the number of oral symptoms and poorer psychological well-being (see Table 1).

Those having various oral symptoms were older and lived more often in nursing homes than those not having any oral symptoms. The participants having oral symptoms had lower selfrated health and poorer psychological well-being that those not having oral symptoms. In addition, mortality was higher in the oral symptom groups compared to that of those not having oral symptoms (see Table 2). 
The associations between dentition status, nutritional factors, GI symptoms and eating habits with burden of oral symptoms are shown in table 3 and with the various oral symptoms are shown in Table 4. Malnutrition according to the MNA was significantly associated with the burden of oral symptoms as well as with various oral symptom.

Residents with oral symptoms needed more help in eating than those not having oral symptoms. They also ate more often alone during the main meal. The more the participants had oral symptoms, the larger the proportion who ate little or very little and more often food with a pureed or liquid consistency. The use of protein supplements and energy-/protein-rich meals was associated in a step-wise fashion with the burden of oral symptoms. Dental status was also associated with the burden of oral symptoms: the prevalence of natural teeth only was highest among those with no oral symptoms, whereas the prevalence of edentulousness without dentures was highest among those with three oral symptoms. The more the participants had oral symptoms, the more often they had, vomiting, constipation, and diarrhoea. There were similar difference concerning various oral symptoms compared to those having no oral symptoms (see Table 4).

We performed a fully adjusted multivariate model to explore which characteristics and variables were associated with the burden of oral symptoms. Several gastrointestinal symptoms, nutritional status, and nutritional care factors were associated with burden of oral symptoms whereas age, sex, dependence in physical functioning or comorbidities were not (see Table 5).

Mortality was associated with the burden of oral symptoms even when adjusted for age and sex. In the Cox regression model adjusted for age, sex, having one oral symptom (Group 1) predicted mortality HR 1.19 (95\% CI 1.07-1.32; $\mathrm{p}=0.001$ ), having two oral symptoms (group 
2) HR 1.62 (95\% CI 1.41-1.85, p<0.001) and having three oral symptoms HR 1.70 (95\% CI $1.37-2.12 ; \mathrm{p}<0.001)$.

\section{Discussion}

Our study shows the magnitude of oral symptoms in institutional settings, and how they are both separately and their burden is linearly associated with poor well-being and mortality. Of the residents $(\mathrm{N}=3123)$ living in long-term care settings, $40 \%$ showed at least one oral symptom and the three symptoms examined (dry mouth, chewing problems, and swallowing difficulties) clustered in $4 \%$ of participants. The more the participants had oral problems, the larger the proportions of subjects that were malnourished, ate less and more often alone. The participants with higher burdens of oral symptoms had poorer dental status and more frequent GI symptoms. Higher burden of oral symptoms was linearly associated with poorer psychological well-being and self-rated health and with higher mortality even adjusted for age and sex.

To our knowledge, this is the first study to explore clustering of oral symptoms and the associations of their burden with various outcomes. The strengths of the study include a large and representative sample of all residents of long-term care establishments in Helsinki. Each nurse familiar with the resident was trained thoroughly in performing the assessments and interviews, and the information was collected with the structured questionnaire, validated and used in previous nutrition studies of nursing homes and assisted living facilities in Finland. We used validated MNA, ${ }^{22}$ which is widely used to indicate malnutrition in older people.

One limiting factor was that the oral symptoms were recorded only with single yes/no questions. No formal measurements of dry mouth or tests in difficulties of chewing or swallowing were used, and the assessment was thus based only on the nurses' evaluation, which still may have underestimated the prevalence of oral symptoms. Thus, probably the severe cases were identified thus reinforcing the associations between oral symptoms and 
various characteristics. Due to the cross-sectional nature of the baseline data, it is impossible to draw any conclusions on the causal relationships between the burden of oral symptoms and its associations. The response rate was fairly good. However, those not responding represent probably the frailest part of this population (moderate-severe dementia, not having a proxy) and may underestimate the true prevalence of oral symptoms. Thus, generalizing these findings should be done with caution.

The proportion of residents with chewing problems (26\%), swallowing difficulties (18\%), or dry mouth $(15 \%)$ were similar to or lower compared to those in previous studies concerning long-term care establishments. ${ }^{1,9,11,27}$ Our evaluation methods may explain the differences between the prevalences. The nurses' clinical assessment may not have been as sensitive in identifying these problems as the detailed tests for dry mouth or swallowing.

The novel finding in this study was that the burden of oral symptoms was so strongly and in a stepwise manner associated with malnutrition, eating habits, and GI symptoms. Two in three of those with three oral symptoms were malnourished, nearly one in three ate alone, and four in ten ate little or very little. Malnutrition was very common in this population, especially among those with two or three oral symptoms. The proportions of malnutrition among those residents having increased burdens of oral symptoms were even higher than Cereda and coworkers found in their large meta-analysis (2016) of long-term care settings. ${ }^{28}$ The burden of oral symptoms may lead to poor diet quality among older adults, which may lead to nutrient deficiencies, ${ }^{29,30}$ discomfort when eating, or shame when eating in front of other people. ${ }^{31}$ The burden of oral symptoms was linearly associated with all types of GI symptoms, both constipation and diarrhoea, suggesting that oral symptoms are intertwined with the quality of the diet, poor mobility, and poor drinking. Residents with oral symptom burden also showed poor dentition status, which further contributed to these problems. 
Unexpectedly, some variables such as education, severity of cognitive decline, diabetes, chronic infections, chronic intestinal diseases or psychiatric diseases were not associated with burden of oral symptoms. Low education and cognitive decline have in previous studies been associated with edentulousness. ${ }^{29}$

Malnutrition, poor self-rated health and lower psychological well-being were in a stepwise fashion associated with burden of oral symptoms, which is in line with previous studies.

Several studies have shown that a poor oral health-related quality of life (OHRQoL) rating was associated with risk of malnutrition. ${ }^{31,32}$ A recent review stated that decreased healthrelated quality of life (HRQoL) and severity of dysphagia have an inverse bidirectional relationship. ${ }^{33}$ Furthermore, xerostomia had a significant and negative impact on self-rated health and quality of life. ${ }^{34}$

In line with prior studies the burden of oral symptoms was also significantly associated with mortality. ${ }^{7,29}$ Those with higher burden of oral symptoms also had higher numbers of comorbidities and increased problems in mobility and daily functioning. Indeed, the burden of oral symptoms predicted higher mortality. Several studies have suggested that focusing on oral health problems may benefit institutionalized residents' health outcomes and quality of life. $^{35,36}$

\section{Conclusions/Implications}

The burden of oral health problems is a serious problem in institutional settings. It is associated in a stepwise fashion with malnutrition, gastrointestinal symptoms, psychological well-being, and mortality. It is also associated with higher need for nutritional care.

Clinicians should routinely assess older institutionalized residents' oral health status to improve their well-being. 


\section{References}

1. Liu B, Dion MR, Jurasic MM et al. Xerostomia and salivary hypofunction in vulnerable elders: prevalence and etiology. Oral Surg Oral Med Oral Pathol Oral Radiol 2012;114:5260.

2. Han P, Suarez-Durall P, Mulligan R. Dry mouth: A critical topic for older adult patients. J Prosthodont Res 2015;59:6-19.

3. Huppertz VAL, van der Putten GJ, Halfens RJG, et al. Association between malnutrition and oral health in Dutch nursing home residents: Results of the LPZ study. J Am Med Dir Assoc 2017;18:948-954.

4. El Osta N, Hennequin M, Tubert-Jeannin S, et al. The pertinence of oral health indicators in nutritional studies in the elderly. Clin Nutr 2014;33:316-321.

5. Toniazzo MP, Amorim PS, Muniz FW, Weidlich P. Relationship of nutritional status and oral health in elderly: Systematic review with meta-analysis. Clin Nutr. 2017 Mar 28. [Epub ahead of print]

6. Sura L, Madhavan A, Carnaby G, Crary MA. Dysphagia in the elderly: management and nutritional considerations. Clin Interv Aging 2012;7:287-298.

7. Lindroos E, Saarela RK, Soini H, et al. Caregiver-reported swallowing difficulties, malnutrition, and mortality among older people in assisted living facilities. J Nutr Health Aging 2014;18:718-722.

8. Baijens LW, Clavé P, Cras P, et al. European Society for Swallowing Disorders - European Union Geriatric Medicine Society white paper: oropharyngeal dysphagia as a geriatric syndrome. Clin Interv Aging 2016;11:1403-1428. 
9. Saarela R, Lindroos E, Soini $\mathrm{H}$ et al. Chewing problems and mortality. J Am Geriatr Soc 2011;59:181-183.

10. Fávaro-Moreira NC, Krausch-Hofmann S, Matthys C, et al. Risk Factors for Malnutrition in Older Adults: A Systematic Review of the Literature Based on Longitudinal Data. Adv Nutr 2016;7:507-522.

11. Ramsay SE, Papachristou E, Watt RG, et al. Influence of Poor Oral Health on Physical Frailty: A Population-Based Cohort Study of Older British Men. J Am Geriatr Soc 2018;66:473-479.

12. Budtz-Jørgensen E, Chung JP, Rapin CH. Nutrition and oral health. Best Pract Res Clin Gastroenterol 2001;15:885-896.

13. Tada A, Miura H. Association between mastication and cognitive status: A systematic review. Arch Gerontol Geriatr 2017;70:44-53.

14. Saarela R. Oral and nutritional problems among residents in assisted living facilities. Medical Dissertation. Helsinki: University of Helsinki, 2014.

15. Peyron MA, Woda A, Bourdiol P, Hennequin M. Age-related changes in mastication. J Oral Rehabil 2017;44:299-312.

16. Lee A, Sitoh YY, Lieu PK, et al. Swallowing impairment and feeding dependency in the hospitalised elderly. Ann Acad Med Singapore 1999;28:371-376.

17. Pitkälä KH, Juola AL, Kautiainen H, et al. Education to reduce potentially harmful medication use among residents of assisted living facilities: a randomized controlled trial. $\mathbf{J}$ Am Med Dir Assoc. 2014;15:892-898. 
18. Suominen M, Muurinen S, Routasalo P, et al. Malnutrition and associated factors among aged residents in all nursing homes in Helsinki. Eur J Clin Nutr 2005;59:578-583.

19. Soini H, Suominen MH, Muurinen S, et al. Malnutrition according to the mini nutritional assessment in older adults in different settings. J Am Geriatr Soc 2011;59:765-766.

20. Charlson ME, Pompei P, Ales KL, MacKenzie CR. A new method of classifying prognostic comorbidity in longitudinal studies: development and validation. J Chronic Dis 1987;40:373-383.

21. Rudolph JL, Salow MJ, Angelini MC, McGlinchey RE. The anticholinergic risk scale and anticholinergic adverse effects in older persons. Arch Intern Med 2008;168:508-513.

22. Guigoz Y, Lauque S, Vellas BJ. Identifying the elderly at risk for malnutrition. The Mini Nutritional Assessment. Clin Geriatr Med 2002;18:737-757.

23. Hughes CP, Berg L, Danziger WL, et al. A new clinical scale for the staging of dementia. Br J Psychiatry 1982;140:566-572.

24. Routasalo PE, Tilvis RS, Kautiainen H, Pitkala KH. Effects of psychosocial group rehabilitation on social functioning, loneliness and well-being of lonely, older people: randomized controlled trial. J Adv Nurs 2009;65:297-305.

25. Pitkälä KH, Laakkonen ML, Strandberg TE, Tilvis RS. Positive life orientation as a predictor of 10-year outcome in an aged population. J Clin Epidemiol 2004;57:409-414.

26. Savikko N, Routasalo P, Tilvis RS, et al. Loss of parents in childhood - associations with depression, loneliness, and attitudes towards life in older Finnish people. Int J Older People Nurs 2006;1:17-24. 
27. Lin LC, Wu SC, Chen HS, et al. Prevalence of impaired swallowing in institutionalized older people in Taiwan. J Am Geriatr Soc 2002;50:1118-1123.

28. Cereda E, Pedrolli C, Klersy et al. Nutritional status in older persons according to healthcare setting: A systematic review and meta-analysis of prevalence data using MNA(®). Clin Nutr 2016;35:1282-1290.

29. Saarela RK, Soini H, Hiltunen K, Muurinen S, et al.. Dentition status, malnutrition and mortality among older service housing residents. J Nutr Health Aging 2014;18:34-38.

30. Lindroos E, Jyväkorpi S, Soini H, et al. Swallowing difficulty and nutrient intakes among residents in assisted living facilities in Helsinki. Eur Geriatr Med 2017;8:228-233.

\section{Gil-Montoya JA, Subirá C, Ramón JM, Gonzáles-Moles MA. Oral Health-Related} Quality of Life and Nutritional Status. J Public Health Dent 2008;68:88-93.

32. Kshetrimayum N, Reddy CV, Siddhana S, et al. Oral health-related quality of life and nutritional status of institutionalized elderly population aged 60 years and above in Mysore City, India. Gerodontology 2013;30:119-125.

33. Jones E, Speyer R, Kertscher B, et al. Health-Related Quality of Life and Oropharyngeal Dysphagia: A Systematic Review. Dysphagia 2018;33:141-172.

34. Matear DW, Locker D, Stephens M, Lawrence HP. Associations between xerostomia and health status indicators in the elderly. J R Soc Promot Health 2006;126:79-85.

35. Lemaster M. Pilot program provides oral health services to long term care facility residents through service learning and community partnership. J Am Med Dir Assoc 2013;14:363-366. 
358 36. Ono S, Ishimaru M, Yamana H, et al. Enhanced Oral Care and Health Outcomes Among

359 Nursing Facility Residents: Analysis Using the National Long-Term Care Database in Japan.

360 J Am Med Dir Assoc 2017;18:277.e1-277.e5.

361 Legends to figure:

362 Figure 1. Venn diagram showing clustering of oral symptoms (dry mouth, chewing problems, 363 swallowing difficulties) among institutionalized residents in Helsinki, Finland. 
Table 1. Characteristics of residents in assisted living facilities and nursing homes in Helsinki divided into groups according to their number of oral symptoms (dry mouth, chewing problems, swallowing problems): no oral symptoms (G0), having one oral symptom (G1), having two oral symptoms (G2), having three symptoms (G3).

\begin{tabular}{|c|c|c|c|c|c|c|}
\hline Characteristic & $\begin{array}{l}\text { G0: No oral } \\
\text { problems } \\
\mathrm{N}=1870\end{array}$ & $\begin{array}{l}\text { G1: One oral } \\
\text { problem } \\
\mathrm{N}=789\end{array}$ & $\begin{array}{l}\text { G2: Two oral } \\
\text { problems } \\
\mathrm{N}=354\end{array}$ & $\begin{array}{c}\text { G3: Three } \\
\text { oral problems } \\
\mathrm{N}=110\end{array}$ & $\mathrm{P}^{\mathrm{a}}$ & $\mathrm{P}^{\mathrm{b}}$ \\
\hline Age, mean (SD) & $84(8)$ & $84(8)$ & $85(8)$ & $85(7)$ & 0.005 & n.a. \\
\hline Female $\%$ & 76 & 78 & 78 & 77 & 0.23 & n.a \\
\hline Education <8years, \% & 48 & 51 & 53 & 47 & 0.22 & 0.28 \\
\hline $\begin{array}{l}\text { Living in } \% \\
\text { Nursing home } \\
\text { Assisted living facility }\end{array}$ & $\begin{array}{l}49 \\
51\end{array}$ & $\begin{array}{l}55 \\
45\end{array}$ & $\begin{array}{l}56 \\
44\end{array}$ & $\begin{array}{l}55 \\
45\end{array}$ & 0.004 & 0.004 \\
\hline Self-rated health good, $\%\left(\mathrm{n}\right.$ responders $\left.{ }^{\mathrm{c}}\right)$ & $\begin{array}{c}78 \\
(\mathrm{n}=1320)\end{array}$ & $\begin{array}{c}69 \\
(n=497)\end{array}$ & $\begin{array}{c}59 \\
(\mathrm{n}=184)\end{array}$ & $\begin{array}{c}33 \\
(\mathrm{n}=49)\end{array}$ & $<0.001$ & $<0.001$ \\
\hline Charlson index, mean (SD) & $2.3(1.5)$ & $2.4(1.4)$ & $2.5(1.5)$ & $2.6(1.8)$ & 0.013 & 0.009 \\
\hline Mean number of medications (SD) & $8.2(3.6)$ & $7.8(3.7)$ & $7.5(3.9)$ & $8.0(4.7)$ & 0.002 & 0.002 \\
\hline Drug with anticholinergic property, \%* & 49 & 48 & 43 & 43 & 0.020 & 0.049 \\
\hline Stroke, \% & 25 & 29 & 30 & 36 & $<0.001$ & $<0.001$ \\
\hline Dementia, \% & 73 & 71 & 73 & 63 & 0.11 & 0.049 \\
\hline Psychiatric disease, $\%$ & 11 & 12 & 12 & 9 & 0.72 & 0.45 \\
\hline Parkinson disease, $\%$ & 5 & 6 & 7 & 10 & 0.007 & 0.005 \\
\hline Diabetes, $\%$ & 7 & 5 & 8 & 9 & 0.53 & 0.58 \\
\hline Chronic intestinal disease, $\%$ & 4 & 5 & 4 & 7 & 0.59 & 0.86 \\
\hline Chronic infection, $\%$ & 5 & 5 & 6 & 8 & 0.067 & 0.098 \\
\hline $\begin{array}{l}\text { At least moderate cognitive decline: CDR "memory" } \\
\text { item } \geq 2, \%\end{array}$ & 72 & 70 & 77 & 75 & 0.092 & 0.17 \\
\hline $\begin{array}{l}\text { Able to walk independently indoors (with or without } \\
\text { device), } \%\end{array}$ & 56 & 40 & 27 & 21 & $<0.001$ & $<0.001$ \\
\hline $\begin{array}{l}\text { Dependent in physical functioning: CDR "personal } \\
\text { care" item } \geq 2, \%\end{array}$ & 85 & 88 & 94 & 93 & $<0.001$ & $<0.001$ \\
\hline Psychological wellbeing, mean $(\mathrm{SD})\left(\mathrm{n}\right.$ responders $\left.{ }^{\mathrm{c}}\right)$ & $\begin{array}{c}0.72(0.24) \\
(n=1430)\end{array}$ & $\begin{array}{l}0.69(0.26) \\
(\mathrm{n}=553)\end{array}$ & $\begin{array}{l}0.63(0.29) \\
(\mathrm{n}=209)\end{array}$ & $\begin{array}{l}0.52(0.25) \\
(\mathrm{n}=55)\end{array}$ & $<0.001$ & $<0.001$ \\
\hline Mortality, \% (95\% CI) & $\begin{array}{c}60 \\
(58 \text { to } 62)\end{array}$ & $\begin{array}{c}67 \\
(63 \text { to } 70)\end{array}$ & $\begin{array}{c}76 \\
(71 \text { to } 80)\end{array}$ & $\begin{array}{c}80 \\
(72 \text { to } 87)\end{array}$ & $<0.001$ & $<0.001$ \\
\hline
\end{tabular}

SD: standard deviation, Charlson comorbidity index (Charlson et al. 1987),CDR: Clinical Rating scale (Hughes et al. 1982). Psychological wellbeing (Routasalo et al. 2009). ${ }^{\mathrm{a}} \mathrm{p}$ for linearity. ${ }^{\mathrm{b}} \mathrm{P}$-values adjusted with age and gender. ${ }^{\mathrm{c}}$ Those with severe dementia excluded 
Table 2. Characteristics of residents in assisted living facilities and nursing homes in Helsinki divided into groups according to their oral symptoms (dry mouth, chewing problems, swallowing problems).

\begin{tabular}{|c|c|c|c|c|c|c|}
\hline Characteristic & $\begin{array}{l}\text { No oral } \\
\text { problems } \\
(\mathrm{N}=1870)\end{array}$ & $\begin{array}{l}\text { Dry mouth } \\
(\mathrm{N}=462)\end{array}$ & $\begin{array}{l}\text { Chewing } \\
\text { problems } \\
(\mathrm{N}=817)\end{array}$ & $\begin{array}{l}\text { Swallowing } \\
\text { difficulties } \\
(\mathrm{N}=548)\end{array}$ & $\mathrm{P}^{\mathrm{a}}$ & $\mathrm{P}^{\mathrm{b}}$ \\
\hline Age, mean (SD) & $84(8)$ & $85(7)$ & $85(8)$ & $84(8)$ & $<0.001$ & n.a. \\
\hline Female \% & 76 & 81 & 79 & 74 & 0.020 & n.a. \\
\hline Education <8years, $\%$ & 48 & 53 & 55 & 57 & 0.19 & 0.30 \\
\hline 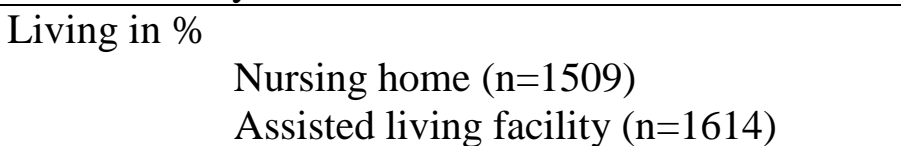 & $\begin{array}{l}49 \\
51\end{array}$ & $\begin{array}{l}53 \\
47\end{array}$ & $\begin{array}{l}56 \\
44\end{array}$ & $\begin{array}{l}61 \\
39\end{array}$ & $<0.001$ & $<0.001$ \\
\hline Self-rated health good, \% (n responders $\left.{ }^{\mathrm{c}}\right)$ & $\begin{array}{c}78 \\
(n=1320)\end{array}$ & $\begin{array}{c}60 \\
(n=327)\end{array}$ & $\begin{array}{c}65 \\
(n=426)\end{array}$ & $\begin{array}{c}52 \\
(n=259)\end{array}$ & $<0.001$ & $<0.001$ \\
\hline Charlson index, mean (SD) & $2.3(1.5)$ & $2.4(1.5)$ & $2.4(1.5)$ & $2.6(1.5)$ & $<0.006$ & $<0.005$ \\
\hline Mean number of medications (SD) & $8.2(3.6)$ & $8.9(4.2)$ & $7.4(3.8)$ & $7.3(3.8)$ & $<0.001$ & $<0.001$ \\
\hline Drug with anticholinergic property, $\%^{*}$ & 49 & 47 & 45 & 43 & 0.055 & 0.072 \\
\hline Stroke, \% & 25 & 27 & 29 & 37 & $<0.001$ & $<0.001$ \\
\hline Dementia, \% & 73 & 60 & 74 & 74 & $<0.001$ & $<0.001$ \\
\hline Psychiatric disease, $\%$ & 11 & 13 & 12 & 10 & 0.38 & 0.10 \\
\hline Parkinson disease, $\%$ & 5 & 8 & 5 & 9 & $<0.001$ & $<0.001$ \\
\hline Diabetes, $\%$ & 7 & 21 & 16 & 16 & $<0.001$ & $<0.001$ \\
\hline Chronic intestinal disease, $\%$ & 4 & 6 & 3 & 4 & 0.17 & 0.20 \\
\hline Chronic infection, $\%$ & 5 & 7 & 6 & 6 & 0.17 & 0.19 \\
\hline $\begin{array}{l}\text { At least moderate cognitive decline: CDR "memory" } \\
\text { item } \geq 2, \%\end{array}$ & 72 & 61 & 78 & 80 & $<0.001$ & $<0.001$ \\
\hline $\begin{array}{l}\text { Able to walk independently indoors (with or without } \\
\text { device), } \%\end{array}$ & 56 & 44 & 32 & 21 & $<0.001$ & $<0.001$ \\
\hline $\begin{array}{l}\text { Dependent in physical functioning: CDR "personal } \\
\text { care" item } \geq 2, \%\end{array}$ & 85 & 82 & 93 & 95 & $<0.001$ & $<0.001$ \\
\hline Psychological wellbeing, mean $(\mathrm{SD})\left(\mathrm{n}\right.$ responders $^{\mathrm{c}}$ ) & $\begin{array}{l}0.72(0.24) \\
(\mathrm{n}=1430)\end{array}$ & $\begin{array}{l}0.61(0.28) \\
(\mathrm{n}=336)\end{array}$ & $\begin{array}{l}0.66(0.27) \\
(\mathrm{n}=475)\end{array}$ & $\begin{array}{l}0.65(0.26) \\
(\mathrm{n}=294)\end{array}$ & $<0.001$ & $<0.001$ \\
\hline Mortality, \% (95\% CI) & $\begin{array}{c}60 \\
(58 \text { to } 62)\end{array}$ & $\begin{array}{c}71 \\
(66 \text { to } 75)\end{array}$ & $\begin{array}{c}72 \\
(69 \text { to } 75)\end{array}$ & $\begin{array}{c}76 \\
(72 \text { to } 79)\end{array}$ & $<0.001$ & $<0.001$ \\
\hline
\end{tabular}

SD: standard deviation, Charlson comorbidity index (Charlson et al. 1987),CDR: Clinical Rating scale (Hughes et al. 1982). Psychological wellbeing (Routasalo et al. 2009). ${ }^{\text {a }}$ Difference between oral symptoms groups were evaluated using generalized estimating equations (GEE) with appropriate distribution and link function. ${ }^{\mathrm{b}} \mathrm{P}$-values adjusted with age and gender. ${ }^{\mathrm{c}}$ Those with severe dementia excluded. n.a.=not applicable. 
Table 3. Nutritional status, nutritional care and oral status and gastrointestinal symptoms of residents in assisted living facilities and nursing homes in Helsinki divided into groups according to their number of oral symptoms (dry mouth, chewing problems, swallowing problems): no oral symptoms (G0), having one oral symptom (G1), having two oral symptoms (G2), having three symptoms (G3).

\begin{tabular}{|c|c|c|c|c|c|c|}
\hline Nutrition & $\begin{array}{l}\text { G0: No } \\
\text { oral } \\
\text { problems } \\
\mathrm{N}=1870\end{array}$ & $\begin{array}{l}\text { G1: One } \\
\text { oral } \\
\text { problem } \\
\mathrm{N}=789\end{array}$ & $\begin{array}{l}\text { G3: Two } \\
\text { oral } \\
\text { problems } \\
\mathrm{N}=354\end{array}$ & $\begin{array}{l}\text { G3: Three } \\
\text { oral } \\
\text { problems } \\
\mathrm{N}=110\end{array}$ & P-value ${ }^{a}$ & $\begin{array}{l}\mathrm{P}_{-} \\
\text {value }^{\mathrm{b}}\end{array}$ \\
\hline \multicolumn{7}{|l|}{ Nutritional status } \\
\hline MNA, \% & & & & & $<0.001$ & $<0.001$ \\
\hline$<17 \mathrm{p}$, malnourished & 17 & 27 & 47 & 64 & & \\
\hline $17-23 p$, at risk for malnutrition & 65 & 65 & 49 & 32 & & \\
\hline$>23.5$, well-nourished & 18 & 9 & 4 & 5 & & \\
\hline \multicolumn{7}{|l|}{ Nutritional care } \\
\hline Feeding & & & & & $<0.001$ & $<0.001$ \\
\hline Eats independently & 57 & 35 & 19 & 19 & & \\
\hline Eats with some assistance & 29 & 33 & 31 & 19 & & \\
\hline Unable to eat without assistance & 18 & 31 & 50 & 62 & & \\
\hline Eats alone & 14 & 17 & 19 & 29 & $<0.001$ & $<0.001$ \\
\hline Consistency of food: liquid or pureed, $\%$ & 7 & 28 & 47 & 60 & $<0.001$ & $<0.001$ \\
\hline Eats little or very little on the main meals, $\%$ & 20 & 29 & 37 & 40 & $<0.001$ & $<0.001$ \\
\hline Eats protein energy supplements, $\%$ & 8 & 12 & 23 & 30 & $<0.001$ & $<0.001$ \\
\hline Energy or protein rich meal, $\%$ & 5 & 9 & 16 & 22 & $<0.001$ & $<0.001$ \\
\hline \multicolumn{7}{|l|}{ Oral status and gastrointestinal symptoms } \\
\hline Dentition status, $\%$ & & & & & $<0.001^{\mathrm{C}}$ & n.a. \\
\hline Edentulous without dentures & 7 & 17 & 23 & 29 & & \\
\hline Edentulous, complete dentures in upper and lower jaw & 26 & 19 & 17 & 18 & & \\
\hline Edentulous, upper or lower complete dentures & 6 & 8 & 8 & 12 & & \\
\hline Natural teeth with one or more dentures & 15 & 17 & 14 & 8 & & \\
\hline Natural teeth only & 45 & 39 & 38 & 33 & & \\
\hline Constipation & 31 & 40 & 51 & 59 & $<0.001$ & $<0.001$ \\
\hline Diarrhoea & 10 & 12 & 12 & 21 & $<0.001$ & $<0.001$ \\
\hline Vomiting & 3 & 5 & 8 & 12 & $<0.001$ & $<0.001$ \\
\hline
\end{tabular}

${ }^{\mathrm{a}} \mathrm{p}$ for linearity; ${ }^{\mathrm{b}}$ Variables tested adjusted with age and gender; ${ }^{\mathrm{c}}$ Differences between groups were tested using the chi-square test. $\mathrm{n} . \mathrm{a} .=$ not applicable. MNA Mini Nutritional Assessment (Guigoz et al.1997) 
Table 4. Nutritional status, nutritional care and oral status and gastrointestinal symptoms of residents in assisted living facilities and nursing homes in Helsinki divided into groups according to their number of oral symptoms (dry mouth, chewing problems, swallowing problems): no oral symptoms (G0), having one oral symptom (G1), having two oral symptoms (G2), having three symptoms (G3).

\begin{tabular}{|c|c|c|c|c|c|c|}
\hline Nutrition & $\begin{array}{c}\begin{array}{c}\text { No oral } \\
\text { problems }\end{array} \\
(\mathrm{N}=1870)\end{array}$ & $\begin{array}{c}\text { Dry } \\
\text { mouth } \\
(\mathrm{N}=462)\end{array}$ & $\begin{array}{l}\text { Chewing } \\
\text { problems } \\
(\mathrm{N}=817)\end{array}$ & $\begin{array}{c}\text { Swallowing } \\
\text { difficulties } \\
(\mathrm{N}=548)\end{array}$ & $\begin{array}{l}\mathrm{P}- \\
\text { value }^{\mathrm{a}}\end{array}$ & $\begin{array}{l}\mathrm{P}^{*_{-}} \\
\text {value }^{\mathrm{b}}\end{array}$ \\
\hline \multicolumn{7}{|l|}{ Nutritional status } \\
\hline MNA, $\%$ & & & & & $<0.001$ & $<0.001$ \\
\hline$<17 \mathrm{p}$, malnourished & 17 & 35 & 39 & 50 & & \\
\hline $17-23 p$, at risk for malnutrition & 65 & 56 & 55 & 46 & & \\
\hline$>23.5$, well-nourished & 18 & 9 & 6 & 4 & & \\
\hline \multicolumn{7}{|l|}{ Nutritional care } \\
\hline Feeding & & & & & $<0.001$ & $<0.001$ \\
\hline Eats independently & 57 & 41 & 24 & 16 & & \\
\hline Eats with some assistance & 29 & 29 & 32 & 27 & & \\
\hline Unable to eat without assistance & 14 & 30 & 43 & 58 & & \\
\hline Eats alone & 14 & 23 & 19 & 19 & $<0.001$ & $<0.001$ \\
\hline Consistency of food: liquid or pureed, $\%$ & 7 & 26 & 43 & 51 & $<0.001$ & $<0.001$ \\
\hline Eats little or very little on the main meals, $\%$ & 20 & 36 & 33 & 35 & $<0.001$ & $<0.001$ \\
\hline Eats protein energy supplements, $\%$ & 8 & 18 & 17 & 24 & $<0.001$ & $<0.001$ \\
\hline Energy or protein rich meal, $\%$ & 5 & 12 & 12 & 18 & $<0.001$ & $<0.001$ \\
\hline \multicolumn{7}{|l|}{ Oral status and gastrointestinal symptoms } \\
\hline Dentition status, $\%$ & & & & & $<0.001$ & $<0.001$ \\
\hline Edentulous without dentures & 7 & 15 & 26 & 22 & & \\
\hline Edentulous, complete dentures in upper and lower jaw & 26 & 24 & 16 & 16 & & \\
\hline Edentulous, upper or lower complete dentures & 6 & 9 & 9 & 8 & & \\
\hline Natural teeth with one or more dentures & 15 & 18 & 14 & 11 & & \\
\hline Natural teeth only & 45 & 34 & 34 & 44 & & \\
\hline Constipation & 31 & 50 & 46 & 49 & $<0.001$ & $<0.001$ \\
\hline Diarrhoea & 10 & 17 & 13 & 13 & $<0.001$ & $<0.001$ \\
\hline Vomiting & 3 & 7 & 7 & 9 & $<0.001$ & $<0.001$ \\
\hline
\end{tabular}

${ }^{a}$ Difference between oral symptoms groups were evaluated using generalized estimating equations (GEE) with appropriate distribution and link function.; ${ }^{b}$ Variables tested adjusted with age and gender; ${ }^{c}$ Differences between groups were tested using the chi-square test. n.a. $=$ not applicable. MNA Mini Nutritional Assessment (Guigoz et al.1997) 
Table 5. Characteristics and variables associated with burden of oral symptoms in multivariate forward stepwise ordered logistic regression analysis. Care site (nursing home s. assisted living facility), comorbidities (Charlson comorbidity index) or dependence in physical functioning were included in the model but were not associated with burden of oral symptoms.

\begin{tabular}{|l|l|l|l|}
\hline & OR & 95\% CI & p value \\
\hline Age & 1.00 & 0.99 to 1.01 & 0.54 \\
\hline Sex & 1.08 & 0.90 to 1.29 & 0.40 \\
\hline MNA, malnourished & 1.00 & & \\
\hline MNA, at risk for malnutrition & 0.50 & 0.41 to 0.59 & $<0.001$ \\
\hline MNA, well-nourished & 0.27 & 0.20 to 0.36 & $<0.001$ \\
\hline Constipation & 1.63 & 1.41 to 1.90 & $<0.001$ \\
\hline Vomiting & 2.42 & 1.72 to 3.41 & $<0.001$ \\
\hline Energy or protein rich meal & 1.65 & 1.25 to 2.18 & $<0.001$ \\
\hline Protein energy supplement & 1.30 & 1.00 to 1.63 & 0.047 \\
\hline Eats little or very little & 1.37 & 1.15 to 1.63 & $<0.001$ \\
\hline Eats alone & 1.26 & 1.04 to 1.53 & 0.020 \\
\hline Number of drugs & 0.98 & 0.96 to 1.00 & 0.071 \\
\hline
\end{tabular}




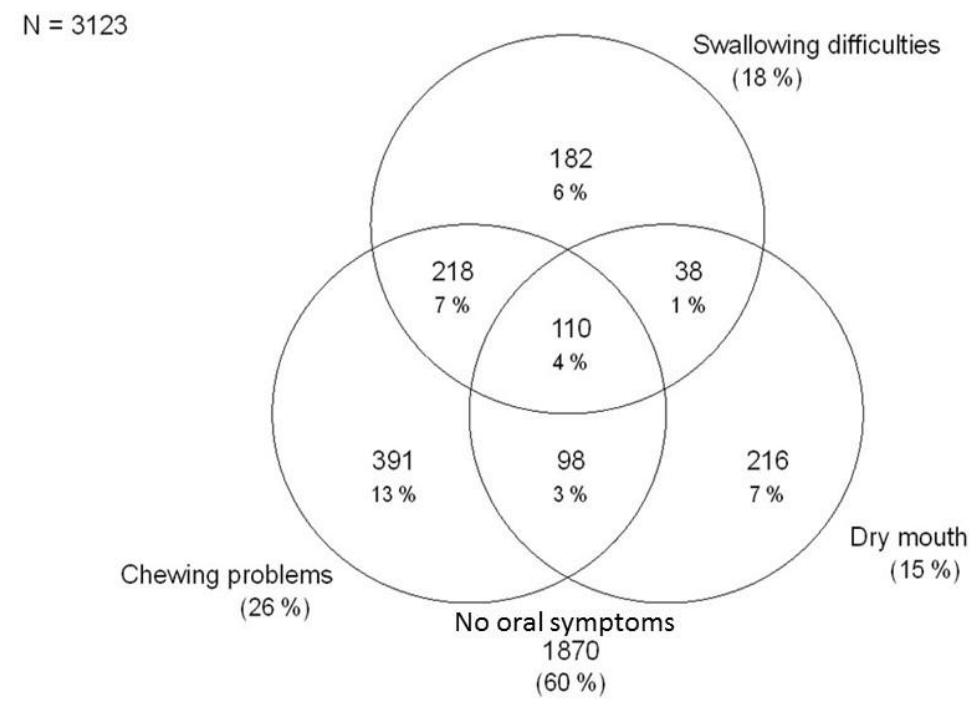

Figure 1. 